\title{
How organisations contribute to improving the quality of healthcare
}

\author{
(c) $($ () $\circledast$ OPEN ACCESS
}

Naomi Fulop and Angus Ramsay argue that we should focus more on how organisations and organisational leaders can contribute to improving the quality of healthcare

\section{Naomi J Fulop professor of healthcare organisation and management, Angus I G Ramsay NIHR knowledge mobilisation research fellow}

UCL Department of Applied Health Research, London, UK; Correspondence to: N J Fulop n.fulop@ucl.ac.uk

\section{Key messages}

The contribution of healthcare organisations to improving quality is not fully understood or considered sufficiently

Organisations can facilitate improvement by developing and implementing an organisation-wide strategy for improving quality

Organisational leaders need to support system-wide staff engagement in improvement activity and, where necessary, challenge professional interests and resistance

Leaders need to be outward facing, to learn from others, and to manage external influences. Strong clinical representation and challenge from independent voices are key components of effective leadership for improving quality

Regulators can facilitate healthcare organisations' contribution by minimising regulatory overload and contradictory demands

Improving the quality of healthcare is complex. ${ }^{12}$ Frontline staff are often seen as the key to improving quality-for instance, by identifying where it can be improved and developing creative solutions. ${ }^{34}$ However, research and reviews of major healthcare scandals acknowledge the contributions of other stakeholders in improving quality, including regulators, policy makers, service users, and organisations providing healthcare. ${ }^{56}$

Policies on the role of organisations in improving quality have tended to focus on how they might be better structured or regulated. However, greater consideration is required of how organisations and their leaders can contribute to improving quality: organisations vary in both how they act to support improvement ${ }^{78}$ and the degree to which they provide high quality healthcare. ${ }^{9}$

Some earlier studies suggest that high performing organisations share several features reflecting organisational commitment to improving quality. These include creating a supportive culture, building an appropriate infrastructure, and embedding systems for education and training. ${ }^{10}{ }^{11}$ Subsequent reviews of quality inspections ${ }^{12}$ and reviews of evidence on factors influencing quality improvement, ${ }^{9}$ and board contributions ${ }^{13}$ indicate that organisational leadership is crucial in delivering high quality care.
We discuss how organisational processes such as development of a strategy and use of data can be used to drive improvement, the characteristics of organisations that are good at improvement, and what to consider when thinking about how organisations can help improve quality of healthcare and patient outcomes.

We present evidence on the role of organisations in improvement drawn from acute hospital settings in the UK and other countries. Although contexts may vary-for example, in whether health policy is made at regional or national level, or in the form and function of healthcare organisations-the lessons have potential relevance to all settings.

\section{Placing healthcare organisations in their context}

Health systems operate at three inter-related levels: macro, meso, and micro (box 1). Research suggests that an organisation-through its leadership and processes—can bridge these levels to influence the quality of care delivered at the front line. ${ }^{14-16}$ 
Box 1: Macro, meso, and micro contributions to the quality of healthcare $^{14}$

$$
\begin{aligned}
& \text { Macro (national health systems) } \\
& \text { - Regulatory system } \\
& \text { - Finance } \\
& \text { - National priorities and policies } \\
& \text { - Accreditation }
\end{aligned}
$$

Meso (hospitals)

- Strategies

- Systems

- Processes

- Cultures

- Practices

- Structures

Micro (departments, teams)

- Relational issues

- Communication

- Professional work

- Competence

A key macro influence on organisations performing their role in improving quality is the way the healthcare system is governed and regulated. Regulation provides accountability to the wider system and therefore has a potentially strong influence on how healthcare organisations approach improvement. For example, multiple regulators in healthcare systems, as is the case in England, can lead to "regulatory overload," 17 making it hard for organisations to focus on quality improvement rather than quality assurance ${ }^{18}$ because of the need to respond to different (and potentially conflicting) regulatory approaches, priorities, incentives, and sanctions. ${ }^{17} 1920$

\section{How can organisations contribute to improving quality?}

Organisations can use various levers and processes to translate external inputs (such as policy and regulatory incentives) and internal inputs (such as local assurance systems providing data on performance and capacity) to support quality improvement. ${ }^{71821}$ Organisations can facilitate improvement by developing and implementing an organisation-wide quality improvement strategy ${ }^{922}$ that includes the following actions:

- Using appropriate data to measure and monitor performance ${ }^{20-22}$

- Linking incentives (both carrot and stick) with performance on quality $^{1622}$

- Recruiting, developing, maintaining, and supporting a quality proficient workforce ${ }^{21}$

- Ensuring sufficient technical resources and building a culture that supports improvement. ${ }^{916}$

Many of the key organisational activities important to improving quality, such as setting strategy and agreeing performance measures, are defined at organisational level by the board. ${ }^{13}$ Bottom-up, clinician-led improvement is often seen as the answer to the quality challenge, and it is an important part of successful quality improvement. ${ }^{324}$ However, relying solely on frontline staff to lead improvement is risky because professional self interest can shape or limit the focus of improvement activity. ${ }^{22526}$ Furthermore, lack of system-wide or organisation-wide agreement on objectives might result in variations at system level, reflecting localised priorities rather than what is likely to provide the best care for patients. As well as empowering staff and supporting system-wide staff engagement in activity around improving quality ${ }^{420}$ organisational leaders must challenge localised professional interests, tribalism, and resistance to change. ${ }^{1822}$

The reorganisation of acute stroke services in the UK (fig 1) shows how leadership can play a pivotal role in managing professional and organisational resistance to changes that aim to improve quality of care. Importantly in this case, leaders cited external organisations' priorities and public consultation responses when holding the line against local resistance to change. ${ }^{25}$

The culture of organisations is commonly considered important in improving quality, as discussed elsewhere in this series. ${ }^{202930}$ Although the relation between culture and quality is complex, organisations can use formal and informal managerial processes to influence culture and thus improve quality of care..$^{30}$

\section{What helps organisations contribute to quality?}

As set out in box 1, the relationship between a healthcare organisation and its external environment (especially regulators) is important in that organisation's contribution to quality. ${ }^{182} \mathrm{~A}$ qualitative study of hospitals and their external environments in five European countries showed how some were better able to align multiple financial and quality demands. ${ }^{7}$ Figure 2 shows contrasting organisational responses to external demands and the features of both the external demands and the organisations that contributed to these different responses.

Organisations can also contribute to improving quality through participation in (or leading) major system change, working beyond their own catchment areas across their local system-for example, integrating health and social care services ${ }^{31}$ or centralising specialist acute services across multiple hospitals in a given area. ${ }^{323}$ Evidence suggests that how such changes are led and implemented influences the impact of the changes, including on patient outcomes (fig 1).

\section{What do organisations that do well in improving quality look like?}

Research suggests that organisations that deliver high quality care show high commitment to improving quality, reflected for instance in how organisations are led (eg, senior management involvement) and managed (eg, use of data and standards). As an illustration, fig 3 contrasts the approaches taken by US organisations with high patient mortality from acute myocardial infarction with those that have low mortality.

Some recent research has developed the concept of maturity in relation to how boards of organisations govern for quality improvement and what organisational processes accomplish and sustain it. ${ }^{18}$

More mature boards tend to use data to drive improvements in quality rather than merely for external assurance, ${ }^{1820}$ and they combine hard quantitative data on performance with soft data on personal experiences to make the case for improvement. ${ }^{22}$ They also engage with relevant stakeholders (including patients ${ }^{18}$ and the public), translate this into strategic priorities, ${ }^{9-11}$ and have processes for managing and communicating information with stakeholders. ${ }^{818}$ They value learning and development ${ }^{472234}$-for example, drawing on external examples of good practice to achieve initial improvement then focusing on local, creative problem solving for continued improvement. ${ }^{34}$ 
Finally, these organisations are outward facing, engaging with and managing their wider environment, including payers and other provider organisations. ${ }^{71329} 34$

By contrast, organisations with lower levels of such capabilities (such as lack of coherent mission, high turnover of leadership, and poor external relationships) appear to slow or limit improvement. ${ }^{183536}$ Some interventions have been identified to help organisations struggling to improve quality. ${ }^{35}$ Furthermore, research on organisational turnaround provides evidence of organisational leaders harnessing crises, such as major safety issues or financial difficulties, to drive radical change and improvement. ${ }^{3637}$ Key changes to turn round organisations have included refocused accountability systems (eg, making quality a key performance indicator, devolving accountability to clinical teams ${ }^{1138}$ ), introducing processes to facilitate improvement (eg, dedicated improvement roles, ${ }^{3638}$ increased training opportunities, and sharing timely data on quality and cost with clinical teams $\mathrm{s}^{113638}$ ), supporting culture change (eg, increasing collaboration between clinicians and management ${ }^{113638}$ with clinicians leading on quality and management supporting them), and learning from the experience of other organisations. ${ }^{113638}$ However, for such interventions to have a chance of success, organisations need both sufficient space to think and the people to make change happen. ${ }^{23}$

The composition of senior leadership seems to influence how well organisations deliver on quality. Having clinicians on the board has been associated with better organisational performance, ${ }^{23} 39$ through enhanced decision making, increased credibility with local clinicians (facilitating frontline uptake of policy), and making organisations more likely to attract talented clinicians. ${ }^{39}$ Active discussion of strategy is enhanced by independent challenge by non-executives who are well versed in quality issues; this is likely to enhance focus on quality at board level, ensuring it is at the heart of an organisation's vision and strategy. ${ }^{13}$ As noted elsewhere, focus is growing on service users guiding improvement. ${ }^{40}$ However, it has been challenging to involve service users meaningfully at senior leadership level. ${ }^{41}$

\section{What can we conclude?}

Although organisations are central to improving quality, there is much variation in how they contribute, both locally and at system level. We have described ways in which organisations can contribute to improvement in terms of their processes (such as how they develop strategy and use data to drive improvements in quality), their leadership (such as how leaders engage with and manage both their external context and local professional interests), and underlying features (including coherence of external demands and leadership stability). Box 2 summarises these themes. However, the balance of priorities among these is unclear: organisations will want to analyse how they can maximise their contribution to improving quality taking account of their particular context.

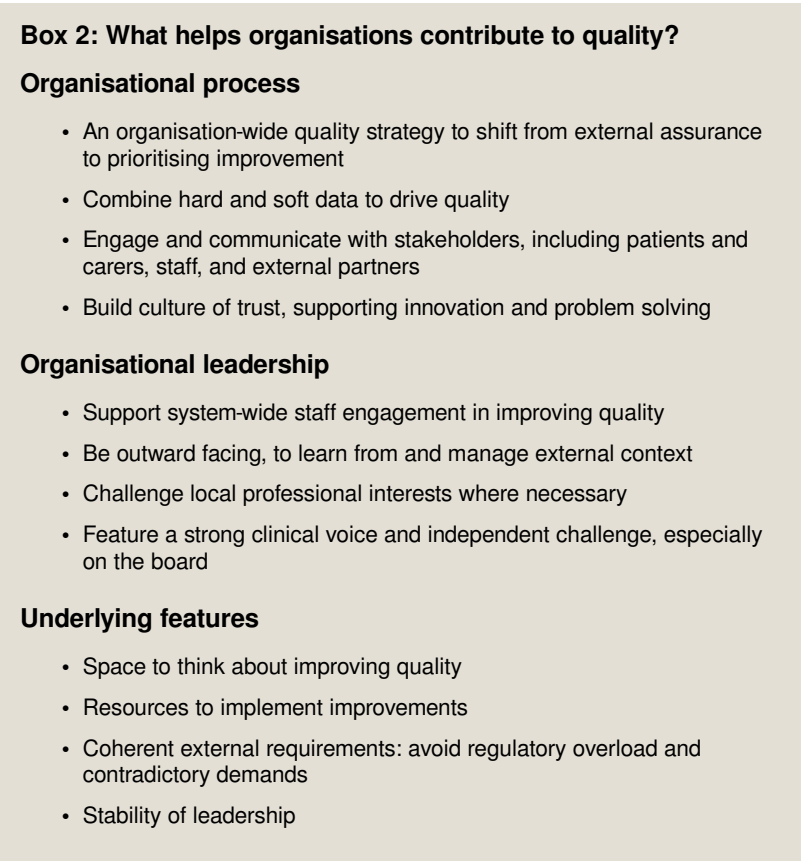

Regulators and policy makers also need to consider how they can better facilitate healthcare organisations' role in improving quality. Organisations are more likely to deliver quality improvement effectively if externally set objectives are clear and manageable, and there is time and resources with which to meet these. Regulators should seek to avoid generating regulatory overload and contradictory demands; and they should strengthen organisational leadership's hand by giving them headspace to look beyond compliance and prioritise improving quality.

Competing interests: We have read and understood BMJ policy on declaration of interests and declare that NJF is an NIHR senior investigator and was in part supported by the NIHR Collaboration for Leadership in Applied Health Research and Care (CLAHRC) North Thames at Barts Health NHS Trust. The views expressed are those of the authors and not necessarily those of the NHS, the NIHR, or the Department of Health and Social Care.

Contributors and sources: Both authors made substantial contributions to the conception and design of the work; to the acquisition, analysis, and interpretation of data; and to drafting the work and revising it critically for important intellectual content. NJF is the guarantor.

This article is part of a series commissioned by The BMJ based on ideas generated by a joint editorial group with members from the Health Foundation and The BMJ, including a patient/carer. The $B M J$ retained full editorial control over external peer review, editing, and publication. Open access fees and The BMSs quality improvement editor post are funded by the Health Foundation

1 Committee on Quality of Health Care in America, Institute of Medicine. Crossing the quality chasm: a new health system for the 21st century. National Academy Press, 2001. Department of Health. An organisation with a memory. Department of Health, 2000.

3 Allwood D, Fisher R, Warburton W, Dixon J. Creating space for quality improvement. BMJ 2018;361:k1924. 10.1136/bmj.k1924 29773587

4 Braithwaite J. Changing how we think about healthcare improvement. BMJ 2018;361:k2014. 10.1136/bmj.k2014 29773537

5 Francis R. Report of the Mid Staffordshire NHS Foundation Trust public inquiry. Stationery Office, 2013.

6 The Bristol Royal Infirmary Inquiry. The Report of the public inquiry into children's heart surgery at the Bristol Royal Infirmary 1984-1995: learning from Bristol. HM Stationery Office, 2001.

7 Burnett S, Mendel P, Nunes F, etal . Using institutional theory to analyse hospital responses to external demands for finance and quality in five European countries. $J$ Health Serv Res Policy 2016;21:109-17. 10.1177/1355819615622655 26683885

8 Curry LA, Spatz E, Cherlin E, etal . What distinguishes top-performing hospitals in acute myocardial infarction mortality rates? A qualitative study. Ann Intern Med 2011;154:384-90. 10.7326/0003-4819-154-6-201103150-00003 21403074

9 Care Quality Commission. Quality improvement in hospital trusts: sharing learning from trusts on a journey of QI. Care Quality Commission, 2018.

10 Baker GR, Macintosh-Murray A, Porcellato C, Dionne L, Stelmacovich K, Born K. High performing healthcare systems: delivering quality by design. Longwoods Publishing, 2008. 
11 Bate P, Mendel P, Robert G. Organizing for quality: the improvement journeys of leading hospitals in Europe and the United States. Radcliffe Publishing Ltd, 200710.1201/b20730

12 NHS Improvement. Developmental reviews of leadership and governance using the well-led framework: guidance for NHS trusts and NHS foundation trusts. NHS Improvement, 2017.

13 Ramsay A, Fulop N, Fresko A, Rubenstein S. The Healthy NHS Board 2013: Review of guidance and research evidence. NHS Leadership Academy, 2013.

14 Robert GB, Anderson JE, Burnett SJ, etal. QUASER team. A longitudinal, multi-leve comparative study of quality and safety in European hospitals: the QUASER study protocol. BMC Health Serv Res 2011;11:285. 10.1186/1472-6963-11-285 22029712

15 Ramsay A, Magnusson C, Fulop N. The relationship between external and local governance systems: the case of health care associated infections and medication errors in one NHS trust. Qual Saf Health Care 2010;19:e45. 10.1136/qshc.2009.037473. 20584705

16 Fulop N, Robert G. Context for successful quality improvement. Health Foundation, 2015. 7 Davies $\mathrm{C}$, Anand $\mathrm{P}$, Artigas L, etal . Links between governance, incentives and outcomes: a review of the literature. Report for the National Co-ordinating Centre for NHS Service Delivery and Organisation R \& D (NCCSDO). NCCSDO, 2005.

18 Jones L, Pomeroy L, Robert G, Burnett S, Anderson JE, Fulop NJ. How do hospital board govern for quality improvement? A mixed methods study of 15 organisations in England. BMJ Qual Saf 2017;26:978-86. 10.1136/bmjqs-2016-006433 28689191

19 Walshe K. The rise of regulation in the NHS. BMJ 2002;324:967-70. 10.1136/bmj.324.7343.967 11964345

20 Dixon-Woods M, Baker R, Charles K, etal . Culture and behaviour in the English National Health Service: overview of lessons from a large multimethod study. BMJ Qual Saf 2014:23:106-15. 10.1136/bmjqs-2013-001947 24019507

21 Gandhi TK, Kaplan GS, Leape L, etal . Transforming concepts in patient safety: a progress report. BMJ Qual Saf 2018;27:1019-26. 10.1136/bmjqs-2017-007756 30018115

22 Dixon-Woods M, McNicol S, Martin G. Ten challenges in improving quality in healthcare: lessons from the Health Foundation's programme evaluations and relevant literature. BMJ Qual Saf 2012;21:876-84. . 10.1136/bmjqs-2011-000760 22543475

23 Jones L, Pomeroy L, Robert $G$, etal Explaining organisational responses to a board-leve quality improvement intervention: findings from an evaluation in six providers in the English National Health Service. BMJ Qual Saf 2019;28:198-204 10.1136/bmjqs-2018-00829130381330

24 Black N. New era for health services will focus on systems and creativity. $B M\lrcorner$ 2018:362:k2605. 10.1136/bmj.k2605

25 Turner S, Ramsay A, Perry C, etal . Lessons for major system change: centralization of stroke services in two metropolitan areas of England. $J$ Health Serv Res Policy 2016;21:156-65. . 10.1177/1355819615626189 26811375

26 Turner S, Ramsay A, Fulop N. The role of professional communities in governing patient safety. J Health Organ Manag 2013;27:527-43. 10.1108/JHOM-07-2012-0138 24003636

27 Fulop NJ, Ramsay AIG, Hunter RM, etal . Evaluation of reconfigurations of acute stroke services in different regions of England and lessons for implementation: a mixed-methods study. Health Services and Delivery Research 2019;7. . 10.3310/hsdr07070 30789689

28 Fulop NJ, Ramsay Al, Perry C, etal . Explaining outcomes in major system change: a qualitative study of implementing centralised acute stroke services in two large metropolitan regions in England. Implement Sci 2016;11:80. 10.1186/s13012-016-0445-z 27255558
29 Damschroder LJ, Aron DC, Keith RE, Kirsh SR, Alexander JA, Lowery JC. Fostering implementation of health services research findings into practice: a consolidated framework for advancing implementation science. Implement Sci 2009;4:50. 10.1186/1748-5908-4-50 19664226

30 Mannion R, Davies $\mathrm{H}$. Understanding organisational culture for healthcare quality improvement. BMJ 2018;363:k4907. 10.1136/bmj.k4907 30487286

31 Exworthy M, Powell M, Glasby J. The governance of integrated health and social care in England since 2010: great expectations not met once again? Health Policy 2017;121:1124-30. 10.1016/j.healthpol.2017.07.009 28811098

32 Moran CG, Lecky F, Bouamra O, etal. Changing the system-major trauma patients and their outcomes in the NHS (England) 2008-17. EClinicalMedicine 2018;4. 10.1016/j.eclinm.2018.11.001

33 Morris S, Hunter RM, Ramsay AIG, etal . Impact of centralising acute stroke services in English metropolitan areas on mortality and length of hospital stay: difference-in-differences analysis. BMJ 2014;349:g4757. 10.1136/bmj.g4757 25098169

34 Nembhard IM, Cherian P, Bradley EH. Deliberate learning in health care: the effect of importing best practices and creative problem solving on hospital performance improvement. Med Care Res Rev 2014;71:450-71. 10.1177/1077558714536619 24876100

35 Vaughn VM, Saint S, Krein SL, etal . Characteristics of healthcare organisations struggling to improve quality: results from a systematic review of qualitative studies. BMJ Qual Saf 2019;28:74-84. 10.1136/bmigs-2017-007573 30045864

36 Harvey G, Jas P, Walshe K. Analysing organisational context: case studies on the contribution of absorptive capacity theory to understanding inter-organisational variation in performance improvement. BMJ Qual Saf 2015;24:48-55. 10.1136/bmjqs-2014-002928 25336092

37 Harvey G, Hyde P, Fulop N, Edwards N, Filochowski J, Walshe K. Recognising. understanding and addressing performance problems in healthcare organisations providing care to NHS patients. Crown, 2006.

38 Jabbal J, Lewis M. Approaches to better value in the NHS: Improving quality and cost. King's Fund, 2018.

39 Sarto F, Veronesi G. Clinical leadership and hospital performance: assessing the evidence base. BMC Health Serv Res 2016;16(Suppl 2):169. 10.1186/s12913-016-1395-5 27230873

40 Dalton J, Chambers D, Harden M, Street A, Parker G, Eastwood A. Service user engagement in health service reconfiguration: a rapid evidence synthesis. J Health Serv Res Policy 2016;21:195-205. 10.1177/1355819615623305 26689536

41 McKevitt C, Ramsay AIG, Perry C, etal . Patient, carer and public involvement in major system change in acute stroke services: the construction of value. Health Expect 2018;21:685-92. 10.1111/hex.12668 29345395

Published by the BMJ Publishing Group Limited. For permission to use (where not already granted under a licence) please go to http://group.bmj.com/group/rights-licensing/ permissionsThis is an Open Access article distributed in accordance with the Creative Commons Attribution Non Commercial (CC BY-NC 4.0) license, which permits others to distribute, remix, adapt, build upon this work non-commercially, and license their derivative works on different terms, provided the original work is properly cited and the use is non-commercial. See: http://creativecommons.org/licenses/by-nc/4.0/. 


\section{Figures}

\section{Leadership}

Combine bottom-up clinical leadership with top-down regional authority
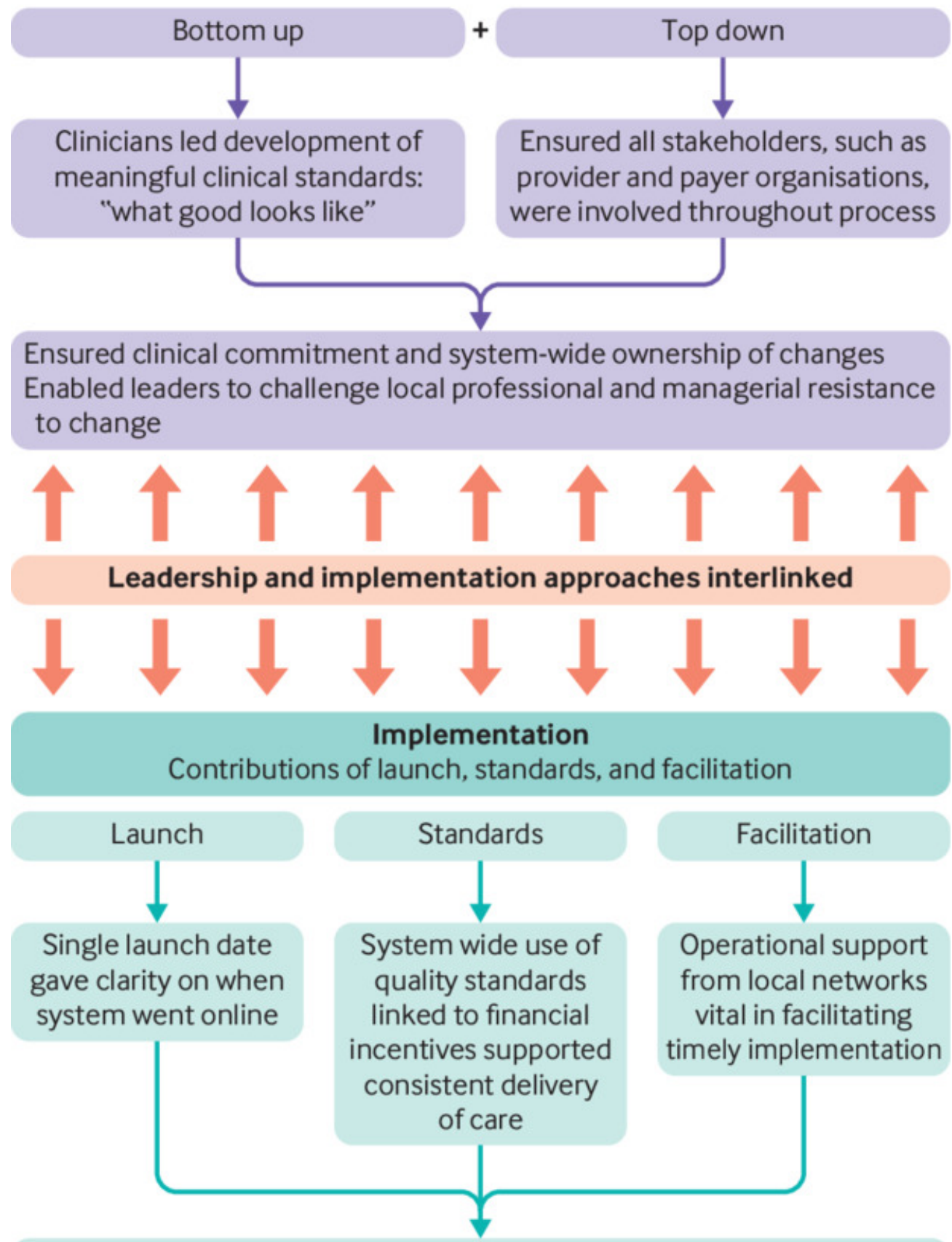

\section{Combined effect:}

Higher proportion of patients treated in specialist unit

Higher likelihood of receiving evidence based care

Significant reductions in patient mortality (eg, 96 additional lives saved

a year in London) and length of hospital stay

Fig 1 Leading and implementing system-wide change across organisations: centralising acute stroke services in London and Greater Manchester 2527 
Response to external demands

Immediate cost

saving measures

Medium term strategies

where quality and

reducing costs not aligned

Medium term strategies where quality and

financial goals aligned

Longer term (at least three years) strategy
Characteristics

Management prioritises financial targets over quality (unless quality targets
were linked to financial incentives)
Lower investment in quality - training cuts, cancelling study leave, and
vacancies frozen, resulting in no time for staff to focus on improvement

Organisations struggled to prioritise between multiple quality demands

Staff became overloaded in trying to meet these demands

Proposals for redesign were met with resistance (perceived as cost cutting)

Staff associated service redesign with increases in quality;

organisations worked with external bodies to negotiate meaningful

objectives balancing finance and improving quality

Focus on embedding quality and financial objectives in day to day activity Organisations invested in developing a capable quality workforce Ongoing dialogue with external bodies to ensure quality and finance objectives aligned
Underlying features

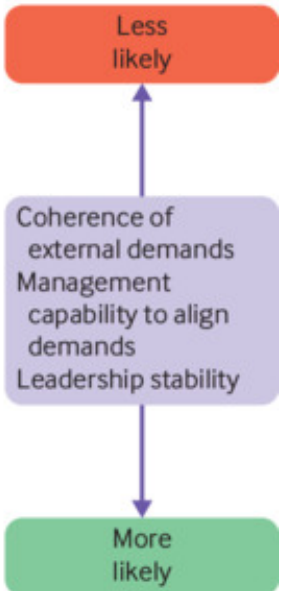

Fig 2 How hospitals respond to external finance and quality demands ${ }^{7}$

TOP 5\% HOSPITALS

risk standardised

mortality rate: 11.4 to 14.0
FEATURE

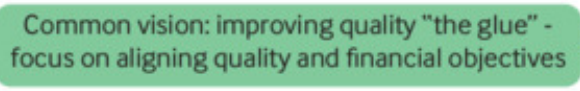

High commitment; use of quality data to guide strategy and accountability; suitable financial and other resources for quality

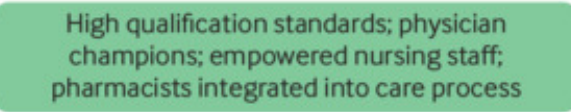

champions; empowered nursing staff; pharmacists integrated into care process

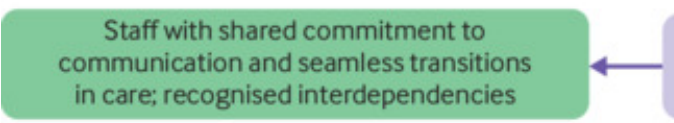

Adverse events used to learn and improve;
data incorporated into organisation;
non-punitive culture; outward focused

No association
with high or low
performance

\section{(1)}

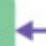

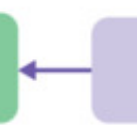
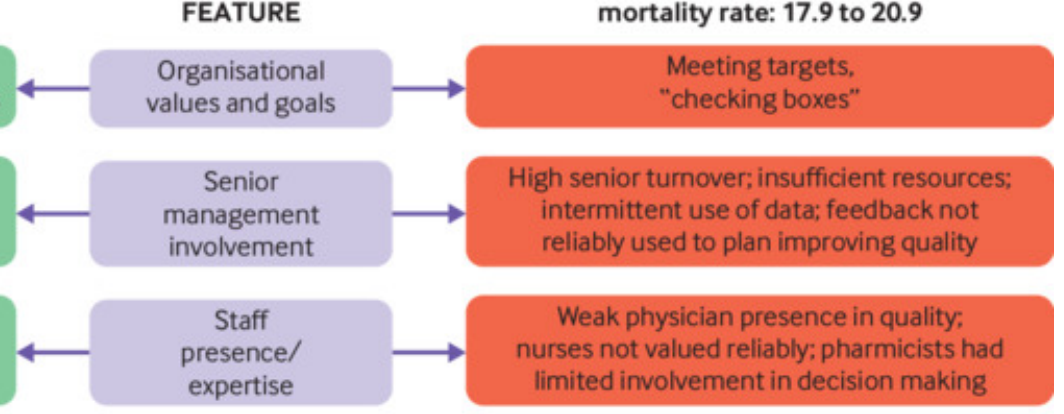

Weak physician presence in quality; nurses not valued reliably; pharmicists had limited involvement in decision making
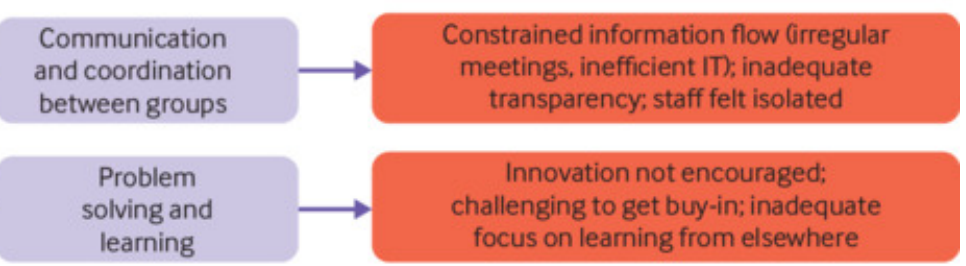

\section{Innovation not encouraged; challenging to get buy-in; inadequate focus on learning from elsewhere}

\section{Protocols and processes \\ for acute myocardial} infarction care

Fig 3 Contrasting organisational approaches in US healthcare organisations with the top and bottom $5 \%$ risk standardised mortality for acute myocardial infarction in $2017^{8}$ 